\title{
A Classroom Research Skills Development Emphasizing Data Analysis and Result of SSRU Students by RBL
}

\author{
Chaiwat Waree $^{1}$ \\ ${ }^{1}$ Faculty of Education, Suan Sunandha Rajabhat University, Bangkok, Thailand \\ Correspondence: Chaiwat Waree, Faculty of Education, Suan Sunandha Rajabhat University, Bangkok, Thailand. \\ Tel: 668-6077-5746. E-mail: chaiwat.wa@ssru.ac.th
}

Received: October 9, 2016

doi:10.5539/ies.v10n4p50
Accepted: November 16, $2016 \quad$ Online Published: March 30, 2017

URL: https://doi.org/10.5539/ies.v10n4p50

\begin{abstract}
The purpose of the study is the learning using research as a base. To strengthen the skills of classroom research Emphasizing Data Analysis and Result and to study the development of research skills in the class Emphasizing Data Analysis and Result of SSRU' Students by learning using research base. The target group are students in the 2nd semester academic year 2557, 159 the sample used to select specific (Purposive Sampling) by researchers as an instructor in the course of the first year students at two and three majors in Thailand, English, Mathematics. The instruments used in the trial, including lesson plans. A pretest-posttest and evaluation of the 25 items and analysis of the data by the percentage of grades and research skills in the classroom and t-test and qualitative data are carried out. The study found that students who meet the grade from $\mathrm{C}+$ to 130 percent 81.76 with students who do not pass the threshold from 29 percent to 18.24 overview of the skills an overview of the rating process skills, research and the two sides are the highest average score was 12.50 , the deviation was 0.72 posttest scores higher than the previous value $t=33.97$ significant level statistically .05 students with the skills to do research on learning and research. The overall satisfaction level of an average value is 4.46 and a standard deviation of 0.68 .
\end{abstract}

Keywords: classroom research skills, emphasizing data analysis, result, RBL

\section{Introduction}

According to instructional condition of Faculty of Education, SSRU, it was found that Standard Deviation was 2.25 with mean of $24.83 \%$, coefficient of variation of $22.66 \%$, percentage of improved students of 73.33 . This would be the result of traditional instruction selected by teacher including lecturing, demonstration, exemplification, addressing some questions, giving some practices emphasizing on passing knowledge from texts without emphasizing on self-development of students upon their potential. It could be seen that the use of abstract media for explaining and holding activities allowing students to think or solve the problems for developing their skills and process is quite low and there was also the lack of learning from daily events or problems of students. Accordingly, learning management process was inconsistent with reality causing students to find no benefit from mathematics learning. Consequently, they lack of attention toward mathematics learning leading them to have learning achievement lower than that defined by school. According to data obtained from questionnaire responded by students, that students had bad attitude of mathematics learning and mathematics is rather considered as difficult subject.

Accordingly, improvement of instruction to be efficient is the responsibility of teachers to seek for methods or strategies to manage mathematics instruction to have the highest level of efficiency and make it as the basic skills lifelong learning.

Research is considered as the important tool to achieve educational reformation. In addition, utilization of research process and research results, especially learning reformation based on research process, is another guideline that teachers and administrators can reform learning in schools. National Education Act B.E. 2542, the parent law of Thai education, emphasizes on research and establishes several sections indicating that research is the process that is conducted along with learning process and work process of persons related to education leading to Knowledge-Based-Society, i.e. Section 24 (5) indicated that research should be able to be used as part of the learning process helping to practice thinking process, management, and reasoning in problem solving as well as to apply knowledge for preventing and solving problems. In addition, Section 30 also defines that 
in-structors should carry out research for developing suitable learning for learners at different level of education. Besides managing instructional process, teachers also utilize researches for studying on problems or anything they want to get answer as well as for developing what they want to develop or solving problems, studying and developing what they consider as problem or want to develop continuously through integrating instructional management process. (Royal Gazette, 1999)

Research Based Learning (RBL) is acquisition of knowledge leading to new knowledge of each field and research process also enables researchers to plan and take action systematically. Consequently, they can discover the truth and build new, correct, and useful knowledge. Moreover, the research also develops researcher's qualifications to have analysis and creativity. Research is the tool for building power and anyone who has self-awareness and self-management will be able to manage environment correctly. Research is a process requiring researchers to think, act, and communicate systematically by using their intellect therefore researchers are able to rely on themselves independently. Research methodology helps to foster researchers to dare to think and make decision reasonably based on existing and sufficient information as well as reliable proof under principles. Accordingly, research based learning is enabling students to learn and use scientific process or inquiry process in the fields related to studied topic to seek for new knowledge or reliable answers. Consequently, it is another guideline for developing students to have basic skills and knowledge for lifelong learning. There are 4 learning guidelines, i.e., teachers use research results in instruction, students use research results in instruction, teachers use research process in instruction, and students use research process in instruction

Development of classroom research skills is emphasized on data analysis and conclusion of students from Faculty of Education of SSRU by 4 formats of RBL emphasizing on integration of instruction and techniques of research-based instruction. The research was conducted throughout a semester in the subjects that were taught by the researcher and the instructional plan was created concretely because instruction in most universities had no instructional plan with complete elements. It was only consisted with Course Specification (TQF.3) specifying topics of learning in each week and most instruction was in the form of lecture. As a result, instructional plan with research-based instructional management was fostering research skills that were integrated with contents of those subjects in order to enable students to have profound-ness in instructional management and complete research skills. Moreover, they would be able to implement obtained skills for solving problems in daily life as well as for managing learning and conducting classroom research for practicing teaching and working as teachers.

\section{Objectives}

1) To implement RBL for developing classroom action research skills emphasizing on data analysis and result conclusion of students of Faculty of Education of SSRU.

2) To study on development of classroom action research skills emphasizing on data analysis and result conclusion of students of Faculty of Education of SSRU.

\section{Scope of Research}

The target group of this research was 159 students of SSRU in all year classes obtained from conducting purposive sampling. The research was teaching Thai, English, and Mathematics to 159 second year and third year students during Semester 2/2014

\section{Conceptual Framework}

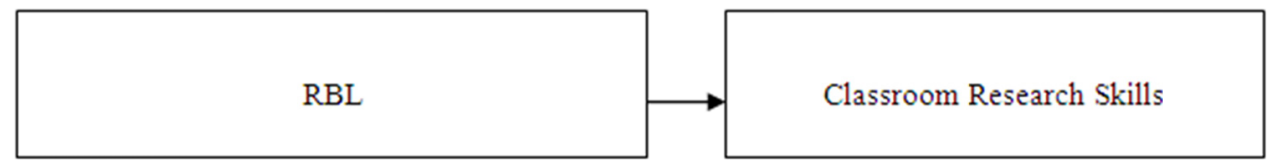

Figure 1. Conceptual framework

\section{Definition}

According to National Education Act B.E. 2542, there is a term, "classroom research" defining that classroom research must be conducted by teachers.

Such definition requires interpretation to find out what classroom research is and what duty of teachers is. 
Firstly, it is necessary to address what classroom research is and research must be consisted of:

1) Problem for conducting research;

2) Causes of such problem;

3) Reliable information acquisition;

4) Discussion for obtaining new knowledge/resolution/answers.

What is Classroom Research?

What is classroom research? Classroom research is the research conducted by teachers that could be observed that some students had some problems. In addition, when considering on the causes of such problems, there were several causes that can be specified. Accordingly, they chose the causes that they can solve (that was not traditional instruction) along teaching majority of students until such problems were resolved. Consequently, the research report with the length of 2-3 pages was written.

Classroom conclusion is the way that teachers solve the problem on some weak students (in some fields) to get the same level of understanding as their classmates or develop some smart students (in some fields) to reach their ultimate potential.

Classroom Research is conducted for whom? Whose is it?

Research for developing students is not conducted as the contribution of the research. On the other hand, student learner development means solving the problem of weak students in order to enable them to get the same level of understanding as other classmates and to promote smart students to reach their ultimate potential.

Research conducted as teacher's contribution should be conducted later and synthesis of resolution of each case should be conducted in order to gain knowledge under the same research problem.

What is the classification of classroom research?

There are various categories of research, for example:

1) Experimental research is consisted of independent variables, dependent variables, control variables, population, sampling, sample groups, and comparison by using statistics for conclusion and referring (F, ANOVA, $\mathrm{t}$ ).

2) Survey research is consisted of research tool (questionnaire, interview), population, sample group, sampling, conclusion and reference based on statistics.

3) Qualitative Research emphasizes on fostering, profoundness, and continuity of researchers in collecting data.

4) Research thesis is suitable for any person aiming for degree and this kind of research is often divided into 5 sections.

5) Quasi-Experiment is a kind of research consisted of independent variables and dependent variables with extraneous variables control. This kind of experiment is conducted with humans but it is also necessary to pay attention on researcher's ethics.

6) Correlational research is consisted of 2 variables and over and correlation of each pair of variables is required.

7) Historical research is a kind of research conducted for studying on the past.

8) Future research is a kind of research conducted based on current condition for predicting future.

9) Researches of various fields such as education, economy, science, laws, etc.

Classroom research is classified in educational field that is conducted by using qualitative research emphasizing on Case Study Research. This case of research is considered as causal study not spatial study.

Research Based Learning means the concept of combination between research and instruction. Good research based learning must be obtained from the curriculum requiring research with research process in learning management in order to make students learn and manage learning. Whereas, students use research tools with learning management by using research results and studied contents, whereas, such research may be conducted by teacher or other persons in studied field.

Research Based Learning can be measured from 2 observed variables including:

1) The Use of Research Process in Learning Management

Procedures of the use of research process in learning management are as follows: 
- Problem Definition

- Hypothesizing

- Data Collection

- Data Analysis

- Conclusion

Teacher held learning activities by using research process started from problem definition to answer estimation or hypothesizing, data collection, data analysis, conclusion, and presentation, respectively, in order to enable students to understand studied contents. In addition, teacher was able to use all procedures of research process or some procedures to meet with learning objectives, learning contents, and limitations.

2) The Use of Research Results for Supporting Learning Management

Teacher held some learning activities by using his/her own works or those of other researchers in the filed related to the topic learned by students or assigning students to study on researches of teacher or other persons related to the topic learned by students.

\section{Guidelines of Research Based Learning}

There are 4 guidelines of Research Based Learning that can be chosen by teachers to suit with subjects, objectives, situations, and potential of students as follows:

Guideline 1: Teacher applies research results to instruction.

Teacher reads research and research results are used in managing his/her own learning in any manner, for example, bring some contents from research results to students for learning or tell such research results to students as additional knowledge.

Guideline 2: Students study on researches related to studied topics.

Teacher assigns students to conduct self-study enabling students to have skills of research consumers and it is the responsibility of teacher to choose research that is appropriate with classes and ages of students or teachers may be responsible for summarizing research to be suitable with students' levels.

Guideline 3: Teacher uses research process in instruction.

Teachers use research process in instruction, i.e., teachers design learning management by using research process for making students to understand demanded contents, whereas, teachers are able to use all procedures of research process or some procedures to meet with learning objectives, learning contents, and limitations.

Guideline 4: Students conduct research on what they are learning.

Teacher assigns students to conduct some researches by themselves under the support of the teacher in order to enable students to conduct their researches upon research procedures to reach the highest level of quality as much as possible.

\section{Research Process}

1) The target group was selected by conducting purposive sampling and the researcher was an instructor of 159 second and third year students who taught in Thai, English, and mathematics of Semester 2/2014. According to curriculum, students of faculty of Education had to study research course in the fourth year and they had to conduct a classroom research project in the fifth year. The overall results of classroom research conducted by students were poor quality and become obstacles of students and advisors. There may be several causes of those obstacles and a major cause was insufficiency of research course that was defined in the fourth year for only one subject. As a result, the researcher required to study on students' behaviors deeply and utilized RBL management with the target students.

2) Instruction of most universities lacked of instructional plan with complete elements. Such instruction was consisted of Course Specification (TQF.3) specifying the topics of each week's instruction only. Since most instruction was in the form of lecture, the researcher decided to perform the instruction based on research-based instructional plan. Such research-based instructional plan was consisted of research title, principles and reasons, expected results, contents, subject matter, learning activities (activity performing and conclusion), learning media, evaluation, and work-sheet. In each instructional plan, there would be the format of RBL integrated in learning activities, namely, 1) research-based instruction; 2) instruction assigning students to make the projects with teachers or being the assistant of teachers' research projects; 3 ) instruction assigning students to study on researches of teachers and leading researchers in the studied fields; and 4) instruction supported by research 
results. It focused on obtaining 2 skills from 5 skills as follows: 1) data analysis; 2) conclusion. There were totally 16 instructional plans with 3 hours per each instruction.

3) Learning result evaluation was testing and evaluating learning result upon the actual condition through observation, inquiry, and evaluation of Rubric Score before reflecting the results to students. The researcher gave independence to students in creating their contributions while the researcher guided them how to seek for and build their own knowledge. The researcher collected data and recorded development of each period in instruction record as well as studied and developed research process skills of each student throughout the semester. The classroom research skills were consisted of: 1) problem addressing; 2) solution or hypothesis determining; 3 ) data investigating and collecting; 4) data analyzing and synthesizing; 5) concluding and reporting. This research aimed to obtain only 3 skills including: 1) data analysis; 2) conclusion because other skills required time for generating.

4) After ending semester, understanding and knowledge of each course as well as classroom research skills were tested by using 60 items of multiple choices examination. Rubric score was used as the score for evaluation of students' works.

5) Data was analyzed and synthesized qualitatively and quantitatively. Subsequently, such data was exhibited in the form of explanation and graph showing classroom research skills development of students. The research was reported in writing.

\section{Conclusion}

Table 1. Research-based instructional management

\begin{tabular}{|c|c|c|c|c|c|c|c|c|c|}
\hline \multirow{2}{*}{ Course } & \multicolumn{9}{|c|}{ Number of Students Classified by Grades } \\
\hline & $\mathrm{A}$ & A- & $\mathrm{B}+$ & $\mathrm{B}$ & B- & $\mathrm{C}+$ & $\mathrm{C}$ & $\mathrm{C}-$ & $\mathrm{F}$ \\
\hline Classroom Management & 11 & 9 & 8 & 6 & 8 & 2 & 2 & - & - \\
\hline $\begin{array}{l}\text { Research for Learning } \\
\text { Development }\end{array}$ & 1 & 14 & 22 & 10 & - & - & - & - & - \\
\hline Mathematic Profile & - & 1 & 1 & 12 & 13 & 12 & 18 & 8 & 1 \\
\hline Total & 12 & 24 & 31 & 28 & 21 & 14 & 20 & 8 & 1 \\
\hline Percentage & 7.55 & 15.09 & 19.50 & 17.61 & 13.21 & 8.81 & 12.58 & 5.03 & 0.63 \\
\hline
\end{tabular}

From Table 1, it was found that the grades of students who mostly learned through RBL were in excellent level or A calculated to be $7.55 \%$ followed by fine calculated to be $15.09 \%$, very good calculated to be $19.50 \%$, good calculated to be $17.61 \%$, quite good calculated to be $13.21 \%$, moderate to quite good calculated to be $8.81 \%$, moderate calculated to be $12.58 \%$, moderate to poor calculated to be $5.03 \%$, and failed calculated to be $0.63 \%$.

Most students were enthusiastic and interested in RBL management for reinforcing classroom research skills. Teachers integrated RBL with activities upon difference of each subject's contents, namely, 1) The research results were utilized by teachers in instruction; 2) The research results were utilized by students in instruction; 3 ) Research process was utilized by teachers in instruction; 4) Research process was utilized by students in instruction. There were 130 students who passed the criteria or gained $\mathrm{C}+$ grade and over calculated to be $81.76 \%$ and there were 29 students who failed calculated to be $18.24 \%$. From interviewing with students who failed the test, it was found that they failed to submit complete tasks and failed to attend the class regularly. Consequently, their scores were insufficient for passing the criteria.

Results of classroom research skills development

1) For data analysis, most students analyzed data appropriately and clearly upon the research objectives. They also prepared some descriptive data and analyzed data for testing hypothesis. This was different from the commencement when students had no idea where to analyze data to meet with research objectives.

2) For conclusion, students were able to conclude the results correctly with direction and accountability. They had to discuss the results in the group for reporting conclusion and discussing obtained results appropriately. 
Table 2. Score of classroom research skills of students of faculty of education

\begin{tabular}{lcccc}
\hline No. & Result Analysis & Conclusion & Average Score & Standard Deviation \\
\hline Mean & 11.89 & 13.11 & 12.50 & 0.86 \\
Standard Deviation & 0.79 & 0.79 & 0.72 & 0.47 \\
\hline
\end{tabular}

From Table 2, the score of capacity to analyze results was in the highest level with mean of 11.89 and Standard Deviation of 0.79. For conclusion, it was in the highest level with mean of 13.11 and Standard Deviation of 0.79. In overall picture, the score of both two aspects of research skills was in the highest level with mean of 12.50 and Standard Deviation of 0.72 .

Table 3. Table exhibiting pre-test and post-test scores and t value

\begin{tabular}{llll}
\hline Test & $\overline{\mathrm{X}}$ & S.D. & $\mathrm{t}$ \\
\hline Pre-Test & 14.20 & 0.96 & \multirow{2}{*}{33.97} \\
Post-Test & 18.74 & 0.99 & \\
\hline
\end{tabular}

From Table 3, it was found that 159 sample students had to do 25 items of test and their average score of pre-test was 14.20 with Standard Deviation of 0.96 considered as moderate level. The average score of post-test was 18.74 with Standard Deviation of 0.99 considered as high level and t was 33.97.

Table 4. Mean and standard deviation (S.D.) was obtained from satisfaction measurement

\begin{tabular}{|c|c|c|c|}
\hline Item & Assessment List & $\bar{X}$ & S.D. \\
\hline 1 & Explanation of classroom research skills was clear and understandable. & 4.38 & 0.65 \\
\hline 2 & Students understand contents of the courses. & 4.33 & 0.67 \\
\hline 3 & Procedures of classroom research skills were clear and appropriate. & 4.78 & 0.56 \\
\hline 4 & Lesson starter was appropriate. & 4.67 & 0.60 \\
\hline 5 & Activities were appropriate and interesting. & 4.00 & 0.80 \\
\hline 6 & Conclusion was appropriate. & 4.73 & 0.50 \\
\hline 7 & Students were the center with participation. & 4.31 & 0.70 \\
\hline 8 & Students were able to ask what questions with teachers. & 4.27 & 0.69 \\
\hline 9 & Tests and practices were appropriate. & 4.33 & 0.71 \\
\hline 10 & Students required research process skills obtained from RBL in other subjects. & 4.84 & 0.42 \\
\hline \multicolumn{2}{|c|}{ Overall Assessment } & 4.46 & 0.68 \\
\hline
\end{tabular}

From Table 4, it was found that students who studied through RBL had high level of satisfaction with $\overline{\mathrm{X}}$ of 4.46 and S.D. of 0.68. Students required research process skills obtained from RBL in other subjects and they also had the highest level of satisfaction with $\overline{\mathrm{X}}$ of 4.84 and S.D. of 0.42 . When considering on each item, it was found that most students had satisfaction in high level.

\section{Discussion}

1) Most students were enthusiastic and interested in RBL management for reinforcing classroom research skills. Teachers integrated RBL with activities upon difference of each subject's contents, namely, 1) The research results were utilized by teachers in instruction; 2) The research results were utilized by students in instruction; 3 ) Research process was utilized by teachers in instruction; 4) Research process was utilized by students in instruction. There were 130 students who passed the criteria or gained $\mathrm{C}+$ grade and over calculated to be $81.76 \%$ and there were 29 students who failed to pass the criteria. This was because the research team mutually held the meeting to find the guidelines of learning management and research leading to the same direction of working for evaluating the results upon actual condition by using various methods and tools making students' grades to be in excellent level and most of them could pass the criteria. This result was consistent with the research of (Sumeth et al, 2004, pp. 406-408) who studied on RBL management: case study of Pramandanijjanukroah School, it was found that RBL management was consisted of 4 elements including teachers' instruction process, teachers' roles, students' learning process, and learning results. This result was consistent with that of Holdsworth (2007) who studied on the results of research-based instruction in 
tele-education of students who were studying stage performance requiring students to learn theoretically and practically through project writing and stage performance organizing. Students had an opportunity to choose their preferred topics under the advice of teachers and information technology was utilized for supporting all processes of this instruction.

2) The results showed that, in overall, the score of classroom research skills of students in both aspects were in the highest level with mean of 12.50 and Standard Deviation of 0.72 and $t$ at 33.97. For the result of satisfaction of students in using RBL skills, in overall, they had satisfaction in high level with $\overline{\mathrm{X}}$ of 4.46 and S.D. of 0.68. These results were consistent with the results of the research conducted by (Waree, Ontkwanmuang, \& Chanfoy, 2016) aiming to implement RBL in reinforcing classroom research skills and to develop classroom research skills of students from Faculty of Education of SSRU by RBL. The target group was consisted 214 students of the second semester of Academic Year 2013. The results showed that there were 204 students who passed the criteria and gained $\mathrm{C}+$ and over calculated to be $95.33 \%$. The overall score of 3 aspects of research process skills was in the highest level with the mean of 11.84 and Standard Deviation of 0.78. This was consistent with the research of (Spronken-Smith, 2007) who studied on how to increase the value of RBL management: case study of knowledge searching from the research project on pollution that integrated research process with instructional management of Bachelor program. The experimental group was consisted of the third year student who were studying Geographic Condition subject. The results showed that the value of RBL could be increased by enabling students to use knowledge searching for their assignments and participated in the research projects with support team. Students had to perceive information from studying and collecting daily data for 2 weeks. For evaluation, it emphasized on group process and it should be conducted periodically started from the commencement of the project in order to improve the operation. The value of the project was increased by making students to understand background and commencement of the use of RBL in this subject, learning on research process, and development of analytical thinking skills.

3) The overall result of satisfaction of students who studied with RBL was in high level with the $\bar{X}$ of 4.46 and S.D. of 0.68. This result was consistent with that of (Na-Songkhla, 2011) studied on development of research-based instruction based on web for knowledge seeking of first year student from Faculty of Education of Chulalongkorn University. The objectives of this research were to develop model and create the compliment media of research-based instruction and to study on the results of research-based instruction based on web for knowledge seeking of students. The results showed that attitude towards knowledge seeking of students before and after RBL based by using web as the instructional media had no difference statistically significant.

\section{Acknowledgments}

This research was supported by SSRU and Higher Education Research Promotion (HERP) in Office of the Higher Education Commission. Special thanks you to all experts and students of SSRU who helped and supported this project.

\section{References}

Holdsworth, N. (2007). Spaces to play/playing with spaces: Young people, citizenship and Joan Littlewood. Research in Drama Education: The Journal of Applied Theatre and Performance, 12(3), 293-304. http://doi.org/10.1080/13569780701560164

Na-Songkhla, J. (2011). No boundaries of Learning: An OpenLearn system at Chulalongkorn University. In S. Barton et al. (Eds.), Proceedings of Global Learn Asia Pacific 2011 (pp. 1639-1641).

Royal Gazette, (1999). National Education Act B.E. 2542. Book No. 116, Part 74 Kor, pp. 21-29.

Spronken-Smith, R. A. (2007). Inquiry-based learning: Meaning, theoretical basis and use in tertiary education. Report prepared for the Ministry of Education, 32pp.

Sumeth, S. et al (2004). The learning of students with the research process: Case Study of Bangkapi School and St. Louis School Education. Bangkok: pramandanijjanukroah school.

Waree, C., Ontkwanmuang, K., \& Chanfoy, P. (2016). A Classroom Research Skills Development of SSRU' Students by RBL, International Journal of Information and Education Technology, 6(11), 899-903. https://doi.org/10.7763/IJIET.2016.V6.813 


\section{Copyrights}

Copyright for this article is retained by the author(s), with first publication rights granted to the journal.

This is an open-access article distributed under the terms and conditions of the Creative Commons Attribution license (http://creativecommons.org/licenses/by/4.0/). 